\title{
SỬ DỤNG HAI ĐộNG MẠCH NGỰC TRONG LÀM TẤT CẢ CÁC CẦU NỐI ĐộNG MẠCH VÀNH TẠI VIỆN TIM TP. HỒ CHÍ MINH: KẾT QUẢ DÀI HẠN
}

Văn Hùng Dũng ${ }^{1,2 *}$, Phạm Thanh Bình ${ }^{1}$, Châu Chí Linh ${ }^{1}$, Hoàng Anh Khôi ${ }^{1}$, Nguyễn Thị Nhu Hà ${ }^{1}$

\section{TÓM TẮT}

Mục tiêu: đánh giá kết quả dài hạn của phẫu thuật bắc cầu động mạch vành (BCĐMV) đơn thuần sử dụng cả hai động mạch ngực trong (ĐMNT) làm toàn bộ cầu nối.

Phưong pháp: nghiên cứu quan sát theo dõi dọc trên nhóm bệnh nhân $(\mathrm{BN})$ được phẫu thuật $\mathrm{BCĐMV} \mathrm{đơn} \mathrm{thuần} \mathrm{chỉ} \mathrm{bằng} 2 \mathrm{ĐMNT}$ trong giai đoạn 2008-2017 tại Viện Tim Thành phố HCM.

Kết quả: tổng số $\mathrm{BN}$ là 246 với tuổi trung bình: $61 \pm 9,1$ năm. Nam giới chiếm 72,3\%. Đau ngực không ổn định trước mổ chiếm $72 \%$. Chỉ số EuroScore II trung bình là 2,53. Tất cả $\mathrm{BN}$ đều có bệnh 3 thân chính ĐMV, 32\% đi kèm hẹp thân chung $>50 \%$. Số cầu nối trung bình cho một $\mathrm{BN}$ là $3,3 \pm 0,55$. Tử vong phẫu thuật $1,6 \%$ (4). Thời gian theo dõi trung bình là $65,9 \pm 40,3$ tháng. Tử vong muộn là $15 \mathrm{BN}$ trong đó, 9/15 trường hợp tử vong liên quan đến tim mạch. Đau ngực tái phát đi kèm bằng chứng khi chụp mạch vành là 10 . Có $4 \mathrm{BN}$ cần tái can thiệp mạch vành sau mổ. Tỉ lệ sống còn sau 12 năm theo Kaplan-Meier cho toàn bộ $\mathrm{BN}$ là $89,1 \pm 3,8 \%$, tỉ lệ không bị can thiệp mạch vành trở lại là 87,8 $\pm 6,3 \%$.

Kết luận: Phẫu thuật $\mathrm{BCĐMV} \mathrm{sử} \mathrm{dụng} \mathrm{cả}$ hai ĐMNT làm toàn bộ cầu nối là an toàn, hiệu quả và cho kết quả về dài hạn rất tốt.

Tù khóa: Bắc cầu ĐMV, Động mạch ngực trong, Toàn bộ cầu nối động mạch, Thông tim can thiệp.

\section{ABSTRACT}

LONG-TERM CLINICAL BENEFIT OF

BILATERAL INTERNAL MAMMARY

ARTERY FOR ISOLATED TOTAL

\section{ARTERIAL REVASCULARIZATION}

Background: we aim to evaluate the longterm outcomes of using Bilateral Internal Mammary Artery (BIMA) for Total Arterial Revascularization (TAR) in coronary artery bypass.

Methods: we conducted a single- center retrospective observational study between 2008 2017 at Ho Chi Minh City Heart Institute-Viet Nam. All patients in study used only BIMA for isolated coronary artery bypass.

Results: total number of patients and mean age were 246 and $61 \pm 9.1$ years. Male patient was $72.3 \%$. Pre-operation, the incidence of unstable angor is $72 \%$ and the mean of EuroScore II is 2.53. All patients had 3-vessel disease with $32 \%$ had left main stenosis. The mean bypass was $3.3 \pm 0.55$ per patient. In-Hospital mortality was $1.6 \%$ (4). Mean time follow-up was $65.9 \pm 40.3$ months. Late death was 15 patients (6\%) among that, there has $9 / 15$ with cardiovascular related death. Incidence of recurrent chest pain with evidence in angiography was 10 . Only 4 patients had to revascularization by PCI. Overall KaplanMeier 12-years survival rate was $89.1 \pm 3.8 \%$ and

\footnotetext{
${ }^{1}$ Viện Tim TP HCM

${ }^{2}$ Đại hoc Y khoa Pham Ngọc Thach

*Tác giả liên hệ:Văn Hùng Dũng. ĐT: 0917882488 ,

Email:vanhungdung@pnt.edu.vn; vanhungdung2003@gmail.com Ngày nhận bài: 21/07/2021 ～Ngày Cho Phép Đăng: 30/09/2021
} 
freedom from reintervention rates for all patients was $87.8 \pm 6.3 \%$.

Conclusions: isolated TAR by BIMA are safe, effective and providing good long-term clinical outcomes in the treatment of 3-vessel coronary disease.

Keywords: coronary artery bypass, BIMA, TAR, PCI

\section{MỞ ĐÀ̀U}

Phẫu thuật bắc cầu động mạch vành (BCĐMV) đã trở thành tiêu chuẩn và thường qui từ những thập niên $80 \mathrm{~s}$. Đã có rất nhiều nghiên cứu về việc lựa chọn mạch ghép cho BCĐMV, đặc biệt là cho động mạch mũ và động mạch vành (ĐMV) phải. Ngoại trừ ĐM ngực trong trái nối xuống ĐM xuống trước trái được xem như là tiêu chuẩn vàng, còn lại ở các vị trí ĐMV khác đã có rất nhiều chọn lựa mạch ghép và nhiều kiểu phối hợp mạch ghép.

Phẫu thuật $\mathrm{BCĐMV} \mathrm{sử} \mathrm{dụng} \mathrm{cả} 2$ động mạch ngực trong (ĐMNT) đã được tác giả Barner (1) giới thiệu hơn 30 năm về trước tuy nhiên đã không được chấp nhận vì rất nhiều lý do, chủ yếu do mất thời gian hơn, kỹ thuật nối phức tạp hơn và nguy cơ làm tăng tỉ lệ nhiễm trùng xương ức sau mổ. Vì vậy, hiện nay trên thế giới chỉ khoảng 10-15\% bệnh nhân (BN) hẹp nhiều nhánh mạch vành được phẫu thuật với kỹ thuật sử dụng cầu nối hoàn toàn bằng 2 ĐMNT. Phức hợp cầu nối (composite graft) giữa ĐMNT trái và phải là kiểu phối hợp được sử dụng nhiều nhất mặc dù đã có nhiều lo ngại việc sử dụng cả hai ĐMNT làm tăng nguy cơ viêm xương ức-trung thất cũng như kỹ thuật thực hiện quá phức tạp và mất thời gian. Nghiên cứu này nhằm mục đích đánh giá kết quả dài hạn của sử dụng hai ĐMNT làm tất cả cầu nối ĐMV tại một trung tâm, một đội ngũ phẫu thuật tim thống nhất cách thức tiến hành.

\section{Đối tựng và Phuơng pháp nghiên cứu:} hồi cứu tất cả các trường hợp $(\mathrm{TH})$ được phẫu thuật BCĐMV tại Viện Tim thành phố Hồ Chí Minh từ tháng 1 năm 2008 đến tháng 12 năm 2017.

Về tiêu chuẩn chọn bệnh: nhóm $\mathrm{BN}$ được đưa vào nghiên cứu bao gồm các $B N$ thỏa 3 tiêu chuẩn sau: (1) chỉ BCĐMV đơn thuần; (2) chỉ sử dụng hai ĐMNT làm tất cả cầu nối (loại trừ các $\mathrm{BN}$ có sử dụng thêm tĩnh mạch hiển hoặc ĐM quay) và (3) BCĐMV có sử dụng tuần hoàn ngoài cơ thể (THNCT). Loại trừ các TH BCĐMV không sử dụng THNCT, BN có phẫu thuật van tim hoặc tim bẩm sinh kèm theo. Nghiên cứu đã được thông qua Hội đồng $\mathrm{Y}$ đức Viện Tim theo quyết định số 1195b/VT-HĐĐĐ ngày 20/08/2019.

\section{Phân tích dĩ liệu}

Dữ liệu có phân phối chuẩn được trình bày dưới dạng trị số trung bình \pm độ lệch chuẩn hoặc trung vị nếu phân phối không chuẩn. Tỷ lệ sống còn thực tế, tỷ lệ không can thiệp lại được tính bằng phương pháp Kaplan-Meier, log-rank (Mantel-Cox) test. Giá trị p $<0,05$ được xem có ý nghĩa thống kê. Phân tích dữ liệu bằng phần mềm IBM-SPSS version 20. Các biến cố cần khảo sát bao gồm tử vong muộn, các biến chứng liên quan về dài hạn như đau ngực tái phát, nhồi máu cơ tim, phải can thiệp lại.

\section{Kết quả:}

Tổng số $\mathrm{BN}$ trong nghiên cứu là 246 với tuổi trung bình là $61 \pm 9,1$ năm (từ 30 đến 81 ). Các đặc điểm dịch tễ và đặc điểm bệnh lý trước mổ được liệt kê trong bảng 1 và bảng 2 . 
Bảng 1: Đặc điểm dịch tễ trước mổ

\begin{tabular}{|l|c|}
\hline \multicolumn{1}{|c|}{ Đặc điểm } & $\mathbf{N}=\mathbf{2 4 6}$ \\
\hline Nam giới & $177(72,3 \%)$ \\
\hline Tuổi trung bình (năm) & $61 \pm 9,1(30-81)$ \\
\hline Bệnh nền & \\
- Tăng huyết áp & $183(74,4 \%)$ \\
- Đái tháo đường & $90(36,6 \%)$ \\
- RLCH lipid & $159(64,4 \%)$ \\
- NMCT cũ & $62(25 \%)$ \\
- Bệnh thận mạn & $22(8,9 \%)$ \\
- COPD & $11(4,5 \%)$ \\
- NMCT cũ & $62(25,2 \%)$ \\
\hline Hút thuốc & $88(35,8 \%)$ \\
\hline PCI trước mố & $25(10,1 \%)$ \\
\hline
\end{tabular}

Bảng 2: Đặc điểm bệnh lý truớc mổ

\begin{tabular}{|c|c|}
\hline \multicolumn{1}{|c|}{ Đặc điểm } & $\mathbf{N}=\mathbf{2 4 6}$ \\
\hline Đau ngực không ổn định & $178(72,3 \%)$ \\
\hline NYHA I & 0 \\
II & $145(58,9 \%)$ \\
III & $92(37,4 \%)$ \\
IV & $09(3,7 \%)$ \\
\hline EuroScore II & $2,53 \pm 1,82$ \\
\hline Bệnh mạch vành & $79(32 \%$ \\
-Hẹp thân chung > 50\% & $246(100 \%)$ \\
-Bệnh ba nhánh & \\
\hline
\end{tabular}

Tổng số cầu nối đã thực hiện là 816 trong đó 3 cầu là $164(66,7 \%)$ và 4 cầu là $74(30,1 \%)$ chiếm $96,8 \%$. Số cầu nối trung bình cho một BN là 3,32 $\pm 0,55$.

Bảng 3: đặc điểm phẫu thuật

\begin{tabular}{|c|c|}
\hline Đặc điểm & $N=246$ \\
\hline Mổ cấp cứu & $25(10,2 \%)$ \\
\hline Số cầu nối trung bình & $3,32 \pm 0,55$ \\
\hline Kiểu cầu nối: Y/T graft & 234 \\
\hline $\mathrm{K}$ graft & 05 \\
\hline Hai cuống song song & 18 \\
\hline Coro-coro ĐMV phải & 12 \\
\hline
\end{tabular}


Tử vong phẫu thuật 1,6\%. Trong $4 \mathrm{TH}$ tử vong, có $2 \mathrm{TH}$ mổ cấp cứu vì nhồi máu cơ tim (NMCT) cấp. 1 TH chết vì nhiễm trùng nặng và 1 TH chết vì suy hô hấp cấp ở trại bệnh.

Theo dõi dài hạn: thời gian theo dõi trung bình là $65,9 \pm 40,3$ tháng (từ 12 đến 156 tháng). Có 5 TH mất theo dõi sau 12 tháng. $75 \%$ số BN được theo dõi tại Viện Tim Thành phố Hồ Chí Minh. Tổng thời gian theo dõi là 15.613 BN-năm.

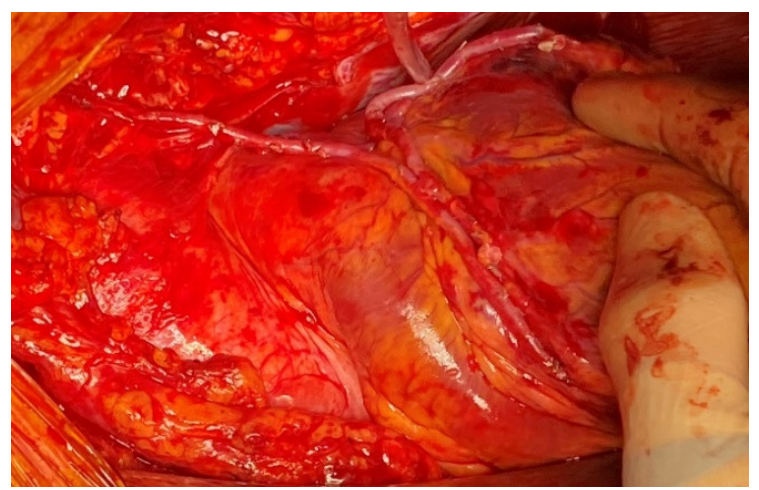

Hình 1a: phức hợp cầu nối kiểu K graft

Đau ngực tái phát đi kèm bằng chứng khi chụp mạch vành là $10(4 \%)$ trong đó NMCT là 3 TH. Chụp mạch vành cho thấy $1 \mathrm{TH}$ hẹp miệng nối ĐMNT- ĐM xuống trước trái, 2 TH hẹp miệng nối ĐMNT phải- ĐM bờ trái, $2 \mathrm{TH}$ hẹp miệng nối ĐMNT phải- ĐM sau bên phải. Còn lại $5 \mathrm{TH}$ là hẹp tiến triển các nhánh khác. Có 4/10 $(1,6 \%) \mathrm{BN}$ cần can thiệp mạch vành sau mổ (2 nong miệng nối trên ĐM xuống trước trái và ĐM bờ trái; $2 \mathrm{TH}$ còn lại, một do tắc cầu nối ĐMNT trái-ĐM xuống trước trái và một nong bổ sung nhánh liên thất sau bên phải). Không có TH nào phải mổ lại. Như vậy, tỉ lệ không bị can thiệp lại sau 12 năm tính theo Kaplan-Meier là $87,8 \pm 6,3 \%$.

\section{BÀN LUẬN}

Sử dụng cả hai ĐMNT để làm cầu nối mạch
Tử vong muộn là $15 \mathrm{BN}(6 \%)$ trong đó, 9/15 trường hợp tử vong có liên quan đến tim mạch, 5 TH chết do ung thư và 1 do suy thận. Loại trừ các $\mathrm{BN}$ chết muộn do nguyên nhân không liên quan tim mạch, tỉ lệ sống còn thực tế sau 12 năm tính theo phương pháp Kaplan-Meier chỉ cho nguyên nhân tử vong do tim mạch $89,1 \pm$ $3,8 \%$ (hình 4); tương tự cho tất cả nguyên nhân là $84,8 \pm 4,3 \%$ (hình 3 ).

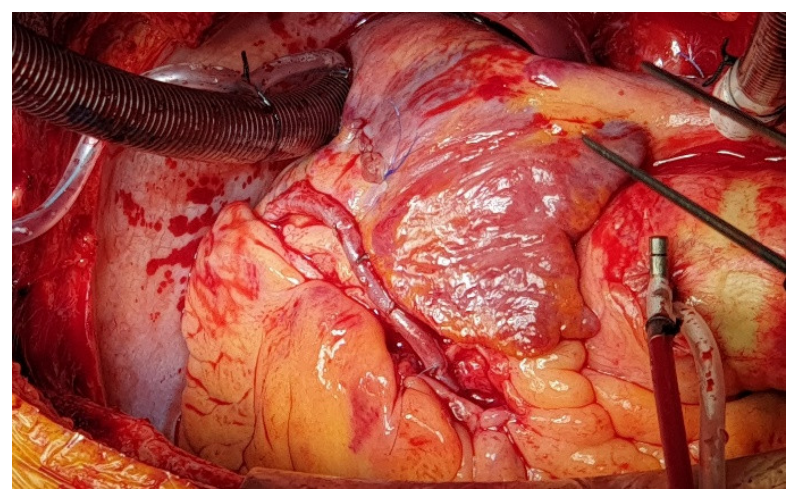

Hình 1b: ĐMNT nối tù đọ̣n 1 đến đọ̣n 3 ĐMV phải

vành đã phát triển từ cuối thập niên 90 s tuy nhiên số BN được sử dụng hai ĐMNT không tăng như mong đợi dù đã có nhiều báo cáo chứng minh tính lợi ích của nó. Đơn cử như nghiên cứu gộp của Taggart năm $2001^{(2)}$ cho thấy tỉ lệ tử vong của nhóm $\mathrm{BN}$ dùng hai ĐMNT được cải thiện đáng kể (tỉ số nguy hại thấp $\mathrm{HR}=0,81$ ). Nghiên cứu so sánh bắt cặp của Lytle năm $2004^{(3)}$ cho thấy tỉ lệ sống còn của nhóm dùng hai ĐMNT được cải thiện ở mọi thời điểm từ 7 cho đến 20 năm sau mổc cụ thể là giảm tỉ lệ tử vong muộn cũng như các biến cố có liên quan tim mạch. Tuy nhiên, vào năm 2010, tỉ lệ dùng hai ĐMNT ở châu Âu chỉ là $10-12 \%$, ở Bắc Mỹ là $4 \%$ tổng số các trường hợp $\mathrm{BCĐMV}{ }^{(4,5,6)}$. Ở châu Á, đặc biệt là Nhật bản và Hàn quốc; cũng như Australia tỷ lệ này cao hơn nhiều. Tại Viện Tim Thành phố 
Hồ Chí Minh chúng tôi đã bắt đầu sử dụng cả hai ĐMNT từ $2008^{(5)}$.

Vì sao phải sử dụng cả hai ĐMNT làm cầu nối? Phân tích dữ liệu trên hơn 1,5 triệu BN trong hệ thống BN ngoại trú quốc gia Hoa Kỳ ${ }^{(6)}$, cho thấy $\mathrm{BN}$ thực hiện cả hai ĐMNT có tỷ lệ tử vong phẫu thuật thấp hơn so với nhóm chỉ một ĐMNT (1,1\% so với $1,7 \%$, OR $0,86,95 \% \mathrm{CI}: 0,79-$ 0,93, $\mathrm{p}<0,001)$. Nghiên cứu của LaPar với 43 823 BN (năm 2015) cho thấy việc sử dụng cả hai ĐMNT không làm tăng nguy cơ tử vong phẫu thuật, biến chứng và thời gian nằm viện ${ }^{(7)}$. Hơn nữa, phân tích gộp của Buttar trên 29 nghiên cứu đã chứng minh rằng nhóm sử dụng cả hai ĐMNT có kết quả dài hạn tốt hơn $(\mathrm{HR}=0,78 ; \mathrm{p}<$ $0,00001)$, và nhóm này có tỷ lệ phải tái tưới máu trở lại thấp hơn có ý nghĩa, $4,8 \%$ so với $10 \%, \mathrm{p}=$ $0,005^{(8)}$. Gần đây nhất, nghiên cứu của Taggart năm 2020 cũng cho thấy nhóm BCĐMV toàn bộ bằng hai ĐMNT có nguy cơ tử vong muộn thấp nhất $(\mathrm{HR}=0,68 ; 95 \% \mathrm{CI}, 0,48-0,96 ; \mathrm{p}=0,03)$ đồng thời giảm có ý nghĩa các biến cố như chết muộn, $\mathrm{NMCT}$, phải tái tưới máu trở lại và đột quy $(\mathrm{HR}=0,71 ; 95 \% \mathrm{CI}, 0,53-0,94 ; \mathrm{P}=0,02)^{(4)}$. Như vậy, kết quả ngắn hạn và dài hạn của phẫu thuật BCĐMV sử dụng cả hai ĐMNT ở các báo cáo nước ngoài đều chứng minh cho ưu thế của hai ĐMNT so với phẫu thuật BCĐMV kinh điển.Về dài hạn, tỷ lệ tử vong muộn trong nghiên cứu của chúng tôi chỉ là 3,6\% nếu chỉ tính nguyên nhân tim mạch và chỉ $1,6 \%$ số $\mathrm{BN}$ cần tái tưới máu lần hai bằng can thiệp mạch (không có $\mathrm{BN}$ nào cần mổ lại), kết quả này tương tự các tác giả nước ngoài. Vì sao có được các kết quả khả quan này? Câu trả lời ở đây đó là sự tồn tại hoạt động (còn thông) của hai cầu nối bằng ĐMNT dài hơn có ý nghĩa khi so với các cầu nối khác như tĩnh mạch hiển hay động mạch quay về dài hạn ${ }^{(2,3,7,8)}$. Và do không phải nối đầu gần hay không tác động đến thành ĐMC lên nên tỉ lệ đột quỵ sau mổ cũng giảm.

Vấn đề lấy cả hai ĐMNT có làm tăng tỷ lệ viêm xương ức-trung thất? Nghiên cứu giải phẫu cho thấy một mạng lưới tuần hoàn bàng hệ lớn được cung cấp máu bởi ĐM cơ hoành, ĐM thượng vị trên và thượng vị dưới, ĐM hoành dưới, các ĐM liên sườn thấp và các nhánh lên cùng $Đ M$ mũ chậu sâu nằm gần với ĐMNT, việc tái tưới máu xương ức sau khi lấy hai ĐMNT không bị ảnh hưởng với điều kiện lấy ĐMNT bằng phương pháp phẫu tích trần và ngừng trước chỗ chia đôi mới bảo đảm còn đủ tuần hoàn bàng hệ. Đã có nhiều nghiên cứu chứng minh hiệu quả của phẫu tích trần như nghiên cứu của Behranwala với phẫu tích trần làm giảm nhiễm trùng xương ức còn $1-2 \%$ so với $10-11 \%$ khi so với nhóm phẫu tích cuống ${ }^{(9)}$. Một phân tích gộp so sánh nguy cơ nhiễm trùng xương ức ở $\mathrm{BN}$ đái tháo đường sử dụng 1 hay 2 ĐMNT cho thấy không có khác biệt về tỉ lệ viêm xương ức nếu ĐMNT được thực hiện phẫu tích trần ${ }^{(10)}$. Nghiên cứu gần đây, năm 2019 của Van den Eynde cũng chứng minh rằng phẫu tích trần cà hai ĐMNT là yếu tố làm giảm biến chứng xương ức có ý nghĩa ở $\mathrm{BN}$ đái tháo đường ${ }^{(11)}$. Ngoài ra, một báo cáo còn cho thấy có việc cải thiện đường kính mạch ghép và tăng lưu lượng máu khi sử dụng phương pháp phẫu tích trần ${ }^{(12)}$. Sau cùng, Davierwala và Mohr đã tổng kết các lý do vì sao phải sử dụng cả hai ĐMNT dựa trên bằng chứng từ gần 100 nghiên cứu trên thế giới và từ nghiên cứu này có thể dẫn ra một số chỉ định sử dụng cả hai ĐMNT 
cho phẫu thuật BCĐMV đơn thuần như BMI < 30 , tuổi $<75$, kiểm soát tốt đái tháo đường, không bị bệnh phổi tắc nghẽn mạn tính ${ }^{(13)}$.

\section{KẾT LUẬN}

Phẫu thuật bắc cầu ĐMV sử dụng cả hai ĐMNT làm toàn bộ cầu nối là an toàn, hiệu quả và cho kết quả về dài hạn rất tốt. Cần tuân thủ đầy đủ các chỉ định và chống chỉ định sử dụng cả hai ĐMNT nhằm tối ưu lợi ích dài hạn của phẫu thuật $\mathrm{BCĐMV}$. Từ kết quả của nghiên cứu này và các nghiên cứu trên thế giới, với các $\mathrm{BN}$ không có chống chỉ định sử dụng cả hai ĐMNT, cần mạnh dạn thực hiện vì lợi ích dài hạn của $\mathrm{BN}$.

\section{TÀI LIỆU THAM KHẢO}

1. H.B.Barner. Double internal mammarycoronary artery bypass. Arch Surg 1974; 109(5): 627-30.

2. D.P.Taggart, R.D'Amico, and D.G.Altman. Effect of arterial revascularisation on survival: a systematic review of studies comparing bilateral and single internal mammary arteries. Lancet 2001; 358(9285): 870-5.

3. B.W. Lytle, E.H.Blackstone, et al. The effect of bilateral internal thoracic artery grafting on survival during 20 postoperative years. Ann Thorac Surg 2004; 78(6): 2005-14.

4. D.P.Taggart, M.F.Gaudino, S.Gerry, A.Gray, B.Lees, A.Dimagli, et al. Effect of total arterial grafting in the Arterial Revascularization Trial. J Thorac Cardiovasc Surg 2020; March:1-8.

5. Văn Hùng Dũng. Bắc cầu mạch vành sử dụng toàn bộ cầu nối là động mạch. Chuyên đề tim mạch học 2010; 9: 13-17.

6. S.Itagaki, P.Cavallaro, et al. Bilateral internal mammary artery grafts, mortality and morbidity: an analysis of 1526360 coronary bypass operations. Heart 2013; 99(12): 849-53.
7. D.J. LaPar, I.K.Crosby, J.B. Rich, M.A. Quader, A.M. Speir, J.A. Kern et al. Bilateral Internal Mammary Artery Use for Coronary Artery Bypass Grafting Remains Underutilized: A Propensity-Matched Multi-Institution Analysis. Ann Thorac Surg 2015;100: 8-15.

8. S.N. Buttar, T.D. Yan, D.P. Taggart, D.H.Tian . Long-term and short-term outcomes of using bilateral internal mammary artery grafting versus left internal mammary artery grafting: a meta-analysis. Heart 2017; 103:1419-1426.

9. A.A. Behranwala, S.G. Raja, and J. Dunning. Is skeletonized internal mammary harvest better than pedicled internal mammary harvest for patients undergoing coronary artery bypass grafting? Interact Cardiovasc Thorac Surg 2005; 4(6): 577-82.

10. S.V. Deo, I.K. Shah, S.M. Dunlay, P.J. Erwin, C. Locker et al. Bilateral Internal Thoracic Artery Harvest and Deep Sternal Wound Infection in Diabetic Patients. Ann Thorac Surg 2013; 96(6): 862-9.

11. V.J. Eynde, A. Heeren, D. Szecel, B. Meuris, S. Jacobs, P. Verbrugghe. Skeletonisation contributing to a reduction of sternal wound complications: a retrospective study in OPCAB patients. J Cardiothorac Surg 2019;14:162-172 .

12. Y. Takami and H. Ina. Effects of skeletonization on intraoperative flow and anastomosis diameter of internal thoracic arteries in coronary artery bypass grafting. Ann Thorac Surg 2002; 73(5):1441-5.

13. P.M. Davierwala and F.W. Mohr. Bilateral internal mammary artery grafting: rationale and evidence. Int J Surg 2015;16(Pt B):133-9 